\title{
Calcinosis Cutis and Intestinal Pseudoobstruction in a Patient with Adult Onset Still's Disease Associated with Recurrent Relapses of Disordered Coagulopathy
}

\author{
Tadashi Shinohara, Toshihiko HidaKa, Yasunori Matsuki, Kimihiro Suzuki and Fumitaka Ohsuzu
}

\begin{abstract}
Adult onset Still's disease (AOSD) is a systemic inflammatory disorder of unknown origin, characterized by a typical spiking fever, evanescent salmon-colored rash, polyarthralgia, and myalgia. Calcinosis cutis and gastrointestinal involvement have rarely been noted in AOSD. We herein describe a 54-year-old woman who demonstrated repeated disseminated intravascular coagulation (DIC), and adult respiratory distress syndrome (ARDS), associated with AOSD. The patient also revealed a remarkable degree of digital calcinosis cutis and intestinal pseudoobstruction. A connective tissue disease, such as systemic sclerosis, might have been the underlying factor in the latter two symptoms.

(Internal Medicine 38: 516-520, 1999)
\end{abstract}

Key words: disseminated intravascular coagulation (DIC), adult respiratory distress syndrome (ARDS)

\section{Introduction}

Adult onset Still's disease (AOSD) is one of the febrile disorders of unknown etiology, characterized by a typical spiking fever, evanescent salmon-colored rash, polyarthralgia, and myalgia $(1,2)$.

Calcinosis cutis has been occasionally noted in connective tissue diseases, such as dermatomyositis and scleroderma (3, 4), but has only rarely been described in AOSD. We observed an AOSD patient who showed recurrent disseminated intravascular coagulation (DIC), and adult respiratory distress syndrome (ARDS). The patient also revealed a remarkable degree of digital calcinosis cutis and intestinal pseudoobstruction. The latter two symptoms might be related to some other connective tissue disease, such as systemic sclerosis (SSc) sine scleroderma.

\section{Case Report}

A 54-year-old woman first complained of polyarthralgia and a high spiking fever with a salmon-colored rash on her trunk in December 1992. She was admitted to our hospital on January 26, 1993 (Fig. 1). She had become anorectic two weeks before admission. One week before admission, she developed a high fever (above $38.0^{\circ} \mathrm{C}$ ), chills, and general malaise.
At the time of her initial physical examination she was 157.5 $\mathrm{cm}$ tall, weighed $48.6 \mathrm{~kg}$, had a temperature of $36.1^{\circ} \mathrm{C}$, a regular pulse of 108 beats per minute, and a blood pressure of $116 /$ $84 \mathrm{mmHg}$. Her skin was slightly dry, and her tongue was dry and brown. The oropharynx was not erythematous and no exudate was observed. No signs of anemia, jaundice, lymph node swelling, nor goiter were revealed. Her heart sound was clear. Auscultation of the lungs revealed no rales and her heart function sounded normal. No abdominal abnormalities were noted. Symmetric arthritidies of the 2nd and 3rd metacarpophalangeal and proximal interphalangeal joints, wrists, shoulders, and knees were observed. Calcinosis cutis was noted around the bilateral interphalangeal and metacarpophalangeal joints on plane radiograph (Fig. 2). Neither tight skin, sclerodactyly, telangiectasia, puffy fingers, nor pitting scars on the digits was present. There was no history of Raynaud's phenomenon.

Laboratory findings showed the erythrocyte sedimentation rate to be $92 \mathrm{~mm} / \mathrm{h}$; C-reactive protein (CRP), $11.9 \mathrm{mg} / \mathrm{dl}$ (normal range; $<0.3$ ); a white blood cell count, $17.7 \times 10^{3} / \mu \mathrm{l}$ (neutrophils $84.0 \%$ ); a hemoglobin level, $12.3 \mathrm{~g} / \mathrm{dl}$; a platelet count, $37.1 \times 10^{4} / \mu$ l. The lactate dehydrogenase $(\mathrm{LDH})$ level was elevated to $538 \mathrm{IU} / l$ (normal; 100-225). The serum Na level was $134 \mathrm{mEq} / l ; \mathrm{K}, 2.9 \mathrm{mEq} / l ; \mathrm{Cl}, 94 \mathrm{mEq} / l$. The serum ferritin level was increased to $3801.5 \mathrm{ng} / \mathrm{ml}$ (normal; 3.4-120). The remaining blood chemistry findings were all within the normal limits.

From the First Department of Internal Medicine, National Defense Medical College, Tokorozawa

Received for publication October 22, 1998; Accepted for publication March 2, 1999

Reprint requests should be addressed to Dr. Tadashi Shinohara, the First Department of Internal Medicine, National Defense Medical College, 3-2 Namiki, Tokorozawa, Saitama 359-8513 


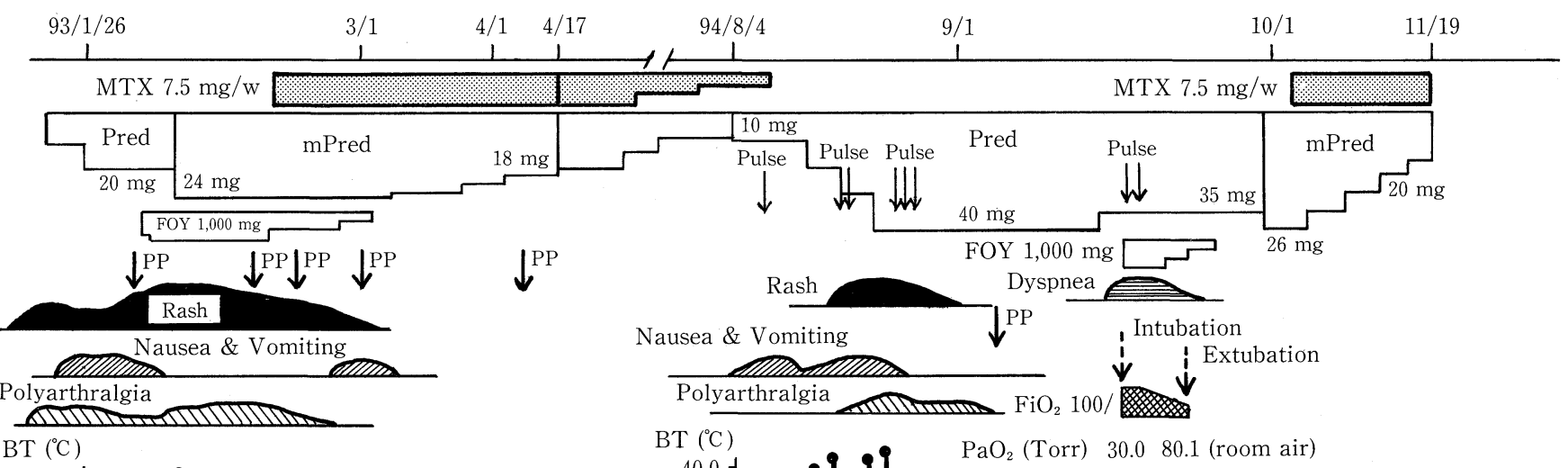

$\mathrm{BT}\left({ }^{\circ} \mathrm{C}\right)$

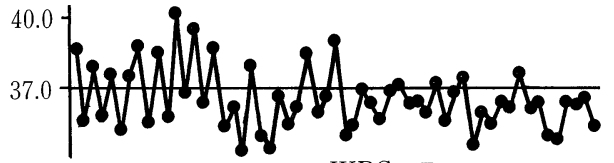

$\mathrm{WBC}\left(\times 10^{4} / \mu 1\right)$

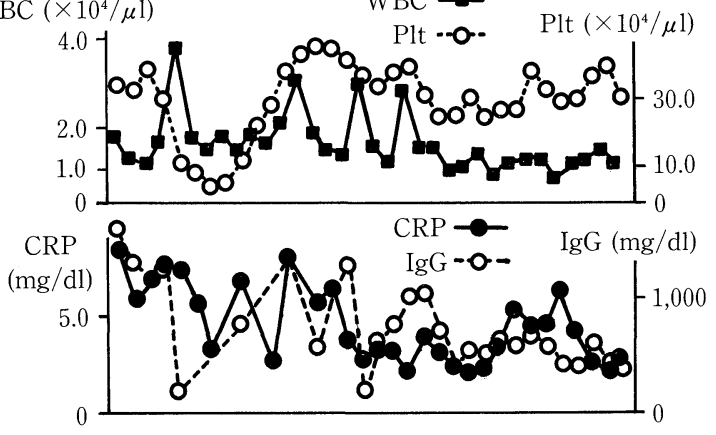

$\begin{array}{lll}\text { FDP } & 20.0 \quad 8.0\end{array}$

$(\mu \mathrm{g} / \mathrm{ml})$

$\begin{array}{lllllll}\text { Ferritin } & 3,801 & 1,834 & 998.2 & 1,015 & 493.4 & 274.6\end{array}$ (ng/ml)

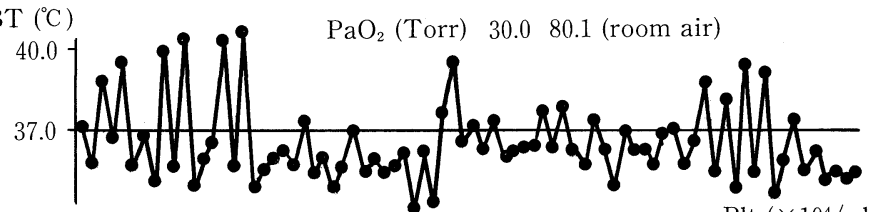

$\mathrm{WBC}\left(\times 10^{4} / \mu 1\right)$
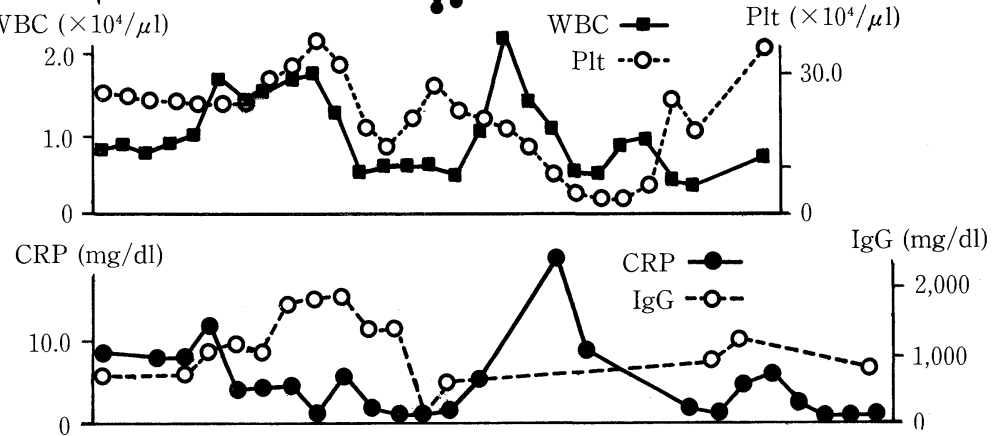

18.0

12.0

26.0

11.0

1,522

27.5

774.3

69.5

34.5

Figure 1. The clinical course. Pred: prednisolone, mPred: methylprednisolone, FOY: gabexate mesilate, PP: double filtration plasmapheresis.

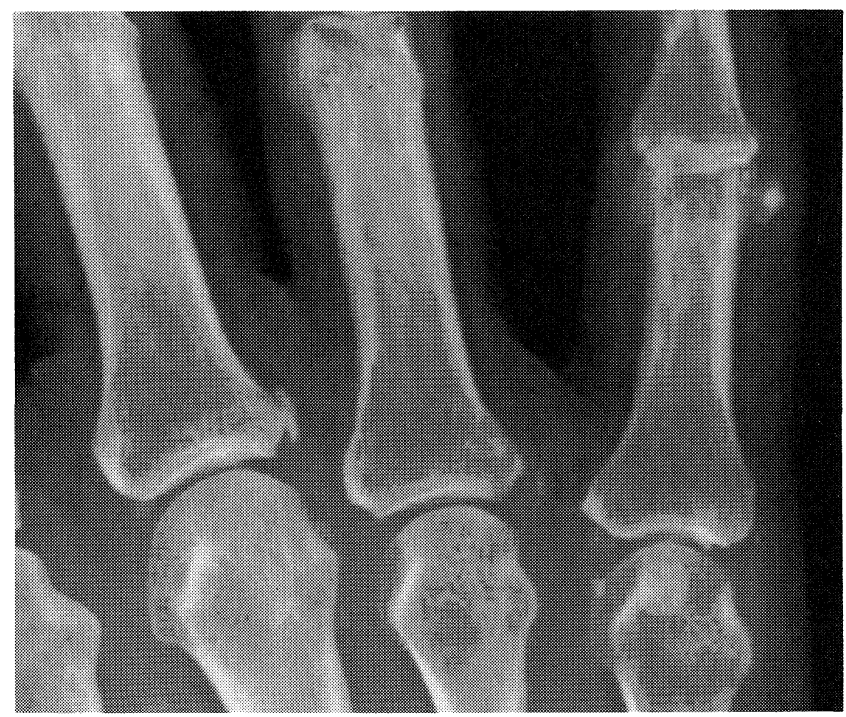

Immunoglobulin (Ig) G was 1,788 mg/dl; IgA, $247 \mathrm{mg} / \mathrm{dl} ; \operatorname{IgM}$, $74 \mathrm{mg} / \mathrm{dl}$. The total hemolytic complement level $\left(\mathrm{CH}_{50}\right)$ was $45.2 \mathrm{U} / \mathrm{ml}$ (normal; 30-40). Antinuclear antibody (ANA) was positive at a titer of 1:1,280 with a proliferating cell nuclear antigen (PCNA)-like staining pattern, but the autoantigen was not PCNA (a $34 \mathrm{kD}$ DNA polymerase- $\delta$ auxiliary protein, ref. \#5), which was confirmed by double immunodiffusion. Rheumatoid factor and any anti-DNA antibodies were not detected. Tests for antibodies against p-ANCA, RNP, SS-A, SS-B, Sm, and Scl-70 antigens all yielded negative results. Further examinations revealed negative serologic findings for both acute and chronic infections. A urinalysis revealed ketonuria and mild

Figure 2. Calcinosis cutis noted around the bilateral Interphalangeal and metacarpophalangeal joints at the first admission on January 26, 1993. 
proteinuria.

A diagnosis of AOSD was made which was consistent with the criteria proposed by Yamaguchi et al (6). Intravenous prednisolone was administered at a dose of $20 \mathrm{mg} /$ day, but the high fever with evening peaks was resistant to this therapy. On February 3 , skin petechiae were first noted on the patient's chest. Two days later, the hemorrhagic tendency increased, and purpura appeared on the bilateral lower limbs, trunk, and oral mucosa. The platelet count suddenly decreased to $7.7 \times 10^{4} / \mu 1$. The FDP level increased to $20 \mu \mathrm{g} / \mathrm{ml}$ (normal; 1-12), while the fibrinogen decreased to $98 \mathrm{mg} / \mathrm{dl}$ (normal;150-450). Antithrombin-III (ATIII) was 45\% (normal; 85-125). She was thus diagnosed to have DIC associated with AOSD, because no other causes of DIC, including bacterial infection, were observed. Heparin, 10,000 units/day, gabexate mesilate (a protease inhibitor), $1,000 \mathrm{mg} /$ day, and ATIII were thus administered, followed by methylprednisolone, $24 \mathrm{mg} /$ day. Double filtration plasmapheresis (DFPP) therapy was first administered on February 3. A total of 5 times of DFPP was performed to remove pathogenic autoantibodies from the circulating blood. Methotrexate therapy $(7.5 \mathrm{mg} /$ week) was initiated on February 19 (Fig. 1). Following these intensive therapies, both the hemorrhagic and inflammatory symptoms improved. After discharge, 8 to $16 \mathrm{mg} /$ day of methylprednisolone and 2.5 to $7.5 \mathrm{mg} / \mathrm{week}$ of methotrexate were administered at our out-patient clinic, and successfully maintained the amelioration for about 16 months.

The patient was readmitted to our hospital on August 4, 1994 because of 'gastrointestinal manifestations (Fig. 1). She complained of epigastric discomfort, dull abdominal pain with nausea and vomiting, and these symptoms all started three days before admission.

At the second admission, her temperature was $36.7^{\circ} \mathrm{C}$; pulse was $96 / \mathrm{min}$ and regular; respiration was at $20 / \mathrm{min}$, and blood pressure was $136 / 76 \mathrm{mmHg}$. The abdomen was slightly distended, and bowel sounds were hyperactive but not metalic. There was a tenderness of the upper umbilical region. No hepatosplenomegaly was observed. A plain radiograph of the abdomen showed air-fluid levels within the dilated loops of the intestine with circular folds (Fig. 3). There was no evidence of mechanical obstruction nor peritonitis.

The laboratory data were as follows; white blood cell count, $12.8 \times 10^{3} / \mu 1$ (neutrophils $79.2 \%$ ); hemoglobin, $12.9 \mathrm{~g} / \mathrm{dl}$; a platelet count, $31.1 \times 10^{4} / \mu \mathrm{l}$; aspartate aminotransferase (AST), $64 \mathrm{IU} / l$; alanine aminotransferase (ALT), $34 \mathrm{IU} / l$; ferritin $1,522.2 \mathrm{ng} / \mathrm{ml}$; CRP, $12.5 \mathrm{mg} / \mathrm{dl} ; \mathrm{IgG}, 1,213 \mathrm{mg} / \mathrm{dl} ; \mathrm{IgA}, 155$ $\mathrm{mg} / \mathrm{dl} ; \mathrm{IgM}, 91 \mathrm{mg} / \mathrm{dl} ; \mathrm{CH}_{50}, 64.5 \mathrm{U} / \mathrm{ml}$. The FDP concentration was $18 \mu \mathrm{g} / \mathrm{ml}$ and D-dimer was $14.7 \mu \mathrm{g} / \mathrm{ml}$ (normal; <1.0). The urinalysis was normal.

The diagnosis was an intestinal pseudoobstruction with a preceding DIC state associated with AOSD. A nasogastric tube was inserted into the stomach for two days. Six days after admission, the patient again began demonstrating an intermittent high fever with evening peaks accompanied by a systemic salmon-colored rash. We repeatedly performed methylprednisolone pulse therapy, and also administered intravenous predniso-

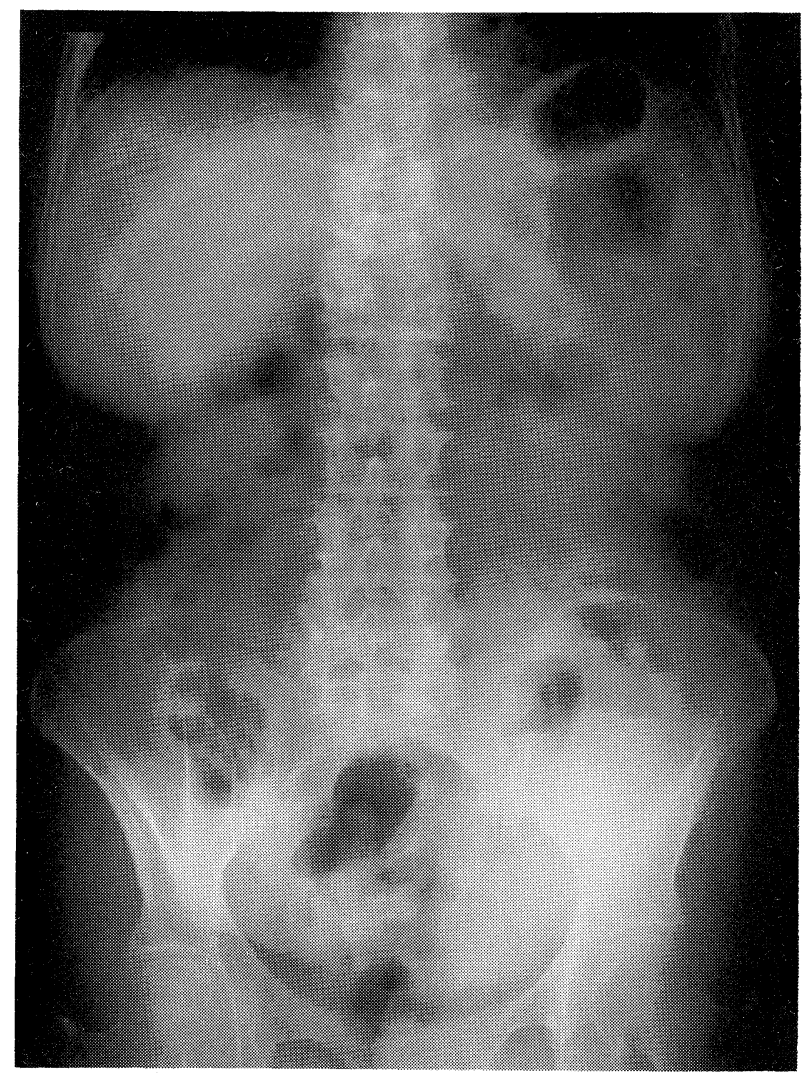

Figure 3. A plain radiograph of the abdomen at the second admission on August 4, 1994, which showed air-fluid levels compatible with an intestinal pseudoobstruction.

lone at an elevated dose of $40 \mathrm{mg} / \mathrm{day}$. These intensive therapies ameliorated the clinical manifestations and laboratory findings.

On September 21, she demonstrated sudden dyspnea. partial pressure of oxygen $\left(\mathrm{PaO}_{2}\right)$ decreased to the level of 30 Torr (Fig. 1), and a chest X-ray showed diffuse infiltrations, especially in the middle and lower fields of the left lung (Fig. 4). There was no pleural effusion. Mechanical ventilation support was started. A bronchoscopic examination revealed remarkable mucosal edema in the vocal cords and throughout the whole main bronchus. Her electrocardiogram revealed a sinus tachycardia. Her echocardiogram revealed no hypokinesis of the left ventricle. These findings were consistent with ARDS. The laboratory findings revealed leukocytosis, $15.6 \times 10^{3} / \mu 1$; CRP, 22.5 $\mathrm{mg} / \mathrm{dl}$; AST, 117 IU/l; ALT, 138 IU/l; LDH, 672 IU/l; FDP, 26 $\mu \mathrm{g} / \mathrm{ml}$; D-dimer, $36.3 \mu \mathrm{g} / \mathrm{ml}$; and decreased platelet count $\left(8.6 \times 10^{4} / \mu 1\right.$ on September 25$)$. The bleeding time, activated partial thromboplastin time (APTT), prothrombin time (PT), and activity of ATIII were within the normal ranges. Serological screening for viral infections, such as rubella and parvovirus B19 was negative. Repeated blood and sputa cultures were also negative. The institution of aggressive medical treatment with anticoagulation and methylprednisolone pulse therapy resulted in improvement of the bronchoscopic abnormalities, chest ra- 


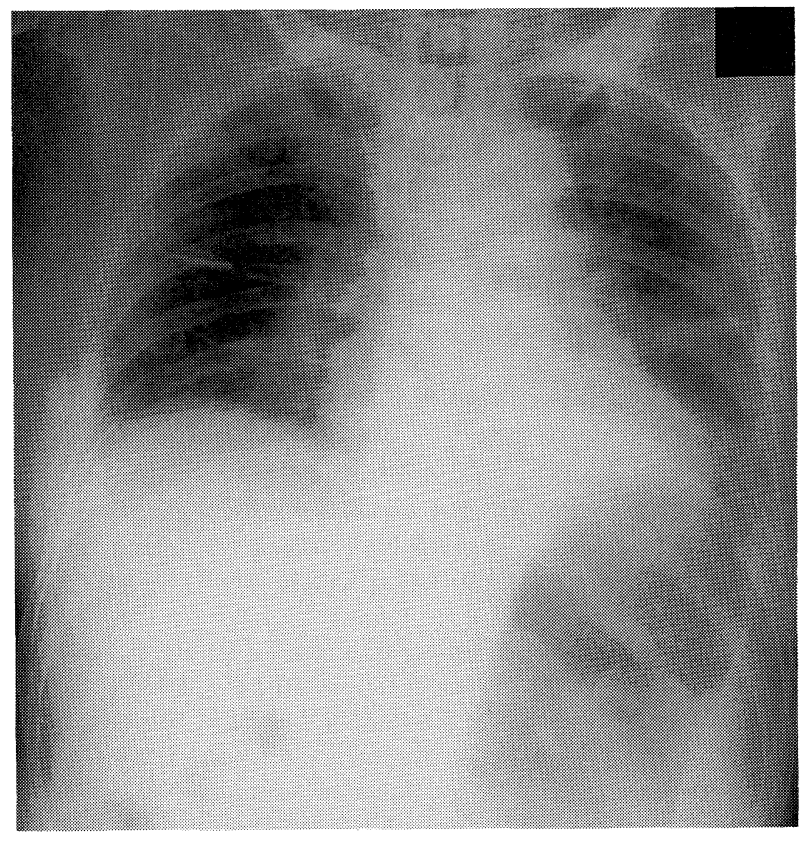

Figure 4. A chest X-ray on September 21, 1994, which showed diffuse infiltrations, especially in the middle and lower fields of the left lung.

diographs, and hypoxemia. She thereafter was taken off mechanical respiratory aid, and was generally active and demonstrated no dyspnea while resting. She was discharged on November 19,1994 . Her prognosis has been thereafter monitored at our out patient clinic.

\section{Discussion}

Dystrophic calcification commonly occurs in connective tissue diseases such as dermatomyositis and scleroderma $(3,4)$, but rarely occurs in AOSD. Cousins et al (3) reported a case of calcinosis cutis universalis in a patient with mild systemic lupus erythematosus (SLE), presenting at the time of initial SLE diagnosis and gradually increasing in size and number. In our patient, the size and number of calcinosis cutis remained unchanged since her first visit to our clinic. The pathophysiology of calcinosis cutis remains unclear. Her serum calcium and phosphate levels were within the normal range throughout her course. Local elevations in alkaline phosphatase activity might lead to hydrolysis of the extracellular pyrophosphates that normally inhibit calcium deposition (3). On the other hand, when phosphate binds to the denatured proteins of necrotic cells at sites of trauma or inflammation, it may serve as a nidus for dystrophic calcification (3).

AOSD cases with both ARDS and DIC have rarely been reported. Coagulopathy in AOSD might be secondary to a continuous activation of the coagulation cascade as a result of failure of the damaged liver to degrade procoagulant factors (7). Hepatic involvement in $\operatorname{AOSD}(1,2,7,8)$ ranges from a mild elevation of liver enzymes to a marked elevation which is unresponsive to treatment. In the present case, the liver damage was mild to moderate at the onset and/or recurrence of DIC.

In some reports $(7,9)$, the recurrent DIC noted in AOSD was attributed to the use of nonsteroidal antiinflammatory drugs (NSAIDs). The disordered coagulation might have been the result of reduced endothelial cell prostacyclin synthesis caused by a high level of unbound nonsteroidal antiinflammatory medication. Our patient had not taken NSAIDs before the onset of DIC. As a result, an underlying clotting abnormality was thus suspected due to some unknown triggering factors in this patient with AOSD.

Recently autoimmune-associated hemophagocytosis has been reported $(10,11)$. Hemophagocytosis is a clinicopathological process that appears to result from uncontrolled activation of inflammatory cytokines, such as interleukin-6 and interferon $\gamma(12)$. Patients with juvenile rheumatoid arthritis who develop hemophagocytosis have also been described based on macrophage activation syndrome (13). In the present case, bone marrow examination was not done, because pancytopenia was negative. We speculate that this case was not complicated by hemophagocytosis.

The relationship between ARDS and DIC has yet to be clearly established $(9,14,15)$. In histologic studies, plateletfibrin thrombi have frequently been found in the lungs of patients dying of ARDS, and DIC was noted in $23 \%$ of ADRS patients in one series (14). Capillary endothelial injuries induced an ARDS state; and injuries such as pulmonary endothelium, unbalanced hemolytic and coagulated state, and the discrimination of abnormal coagulation all seem to comprise the DIC state $(14,15)$. A variety of immunosuppressive drugs for the treatment of AOSD have shown a favorable outcome for such life-threatening cases of coagulopathy.

Her abdominal pain was diagnosed as a pseudoobstruction due to an impairment of gastrointestinal tract motility. There are numerous causes of secondary intestinal pseudoobstruction, including neurologic, endocrine, and connective tissue diseases (16), but rarely in AOSD. When AOSD patients complain of abdominal pain, secondary amyloidosis associated with AOSD (17) should be ruled out. In this case, a gastric mucosa specimen revealed no amyloid protein deposition, and this was further confirmed by Congo Red staining. Further, abdominal lymph node swelling and peritonitis are occasionally noted in AOSD patients (6). In this case, neither were comfirmed by echogram or computed tomography.

Anti-PCNA antibodies were originally identified in the sera of SLE patients (18). Nojima et al (19) reported 2 non-SLE cases with anti-PCNA who developed a severe gastrointestinal dysfunction which eventually led to a chronic intestinal pseudoobstruction. They proposed that systemic sclerosis (SSc sine scleroderma) was the underlying disease in the development of pseudoobstruction in their 2 patients (19). Our AOSD patient did not possess anti-PCNA but did have autoantibodies revealing an anti-PCNA-like staining pattern on immunofluoresence method. Several autoantibodies recognizing cell-cycle related antigens other than anti-PCNA have been reported (20). 


\section{SHINOHARA et al}

The autoantigen and clinical significance of the 'anti-PCNAlike' antibodies noted in this patient are not clear. The presence of calcinosis cutis and intestinal pseudoobstruction indicated that some underlying connective tissue disease, such as SSc, in the pathogenesis. The patient lacked sclerodermatous skin lesions. Nevertheless, it is well known that visceral involvement by SSc frequently occurs in the absence of scleroderma (SSc sine scleroderma). In AOSD, ANA is usually negative, which also supports that some connective tissue disease, such as SSc, might have been present in this patient.

\section{References}

1) Ohta A, Yamaguchi M, Tsunematsu T, et al, Adult Still's disease: A multicenter survey of Japanese patients. J Rheumatol 17: 1058-1063, 1990.

2) Cush JJ, Medsger TA Jr, Christy WC, Herbert DC, Cooperstein LA. Adultonset Still's disease: clinical course and outcome. Arthritis Rheum 30: 186-194, 1987.

3) Cousins MA, Jones DB, Whyte MP, Monafo WW. Surgical management of calcinosis cutis universalis in systemic lupus erythematosus. Arthritis Rheum 40: 570-572, 1997.

4) Czirjác L, Nagy Z, Szegedi G. Systemic sclerosis in the elderly. Clin Rheumatol 11: 483-485, 1992.

5) Prelich G, Tan CK, Kostura M, et al. Functional identity of proliferating cell nuclear antigen and a DNA polymerase-auxiliary protein. Nature 326: 517-520, 1987.

6) Yamaguchi M, Ohta A, Tsunematsu T, et al. Preliminary criteria for classification of adult Still's disease. J Rheumatol 19: 424-430, 1992.

7) Scwartz D, Averbuch M, Pines A, Kornovsky R, Levo Y. Disseminated intravascular coagulation with renal and liver damage as the predominant manifestations of recurrent relapses in systemic juvenile rheumatoid arthritis. Ann Rheum Dis 51: 347-349, 1992.
8) Esdaile JM, Tannenbaum H, Lough J, Hawkins D. Hepatic abnormalities in adult onset Still's disease. J Rheumatol 6: 673-679, 1979.

9) Silverman ED, Miller JJ, Bernstein B, Shafai T. Consumption coagulopathy associated with systemic juvenile rheumatoid arthritis. J Pediatr 103: 872-876, 1983.

10) Wong KF, Hui PK, Chan JK, Chan YW, Ha SY. The acute lupus hemophagocytic syndrome. Ann Intern Med 114: 387-390, 1991.

11) Kumakura $S$, Ishikura $H$, Umegae $N$, Yamagata $S$, Kobayashi S. Autoimmune-associated hemophagocytic syndrome. Am J Med 102: 113-115, 1997.

12) Favara BE. Hemophagocytic lymphohistiocytosis: A hemophagocytic syndrome. Semin Diagn Pathol 9: 63-74, 1992.

13) Stéphan JL, Zeller J, Hubert P, Herbelin C, Dayer JM, Prieur AM. Macrophage activation syndrome and rheumatic disease in childhood: A report of four new cases. Clin Exp Rheumatol 11: 451-456, 1993.

14) Bone RC, Francis PB, Pierce AK. Intravascular coagulation associated with the adult respiratory distress syndrome. Am J Med 61: 585-589, 1976.

15) Windsor AC, Mullen PG, Fowler AA, Sugerman HJ. Role of the neutrophil in adult respiratory distress syndrome. Br J Surg 80: 10-17, 1993.

16) Schuffler MD, Rohrmann CA, Chaffee RG, Brand DL, Delaney JH, Young JH. Chronic intestinal pseudo-obstruction. A report of 27 cases and review of the literature. Medicine (Baltimore) 60: 173-196, 1981.

17) Harrington TM, Moran JJ, Davis DE. Amyloidosis in adult onset Still's disease. J Rheumatol 8: 833-836, 1981.

18) Miyachi K, Fritzler MJ, Tan EM. Autoantibody to a nuclear antigen in proliferating cells. J Immunol 121: 2228-2234, 1978.

19) Nojima Y, Mimura T, Hamasaki K, et al. Chronic intestinal pseudoobstruction associated with autoantibodies against proliferating cell nuclear antigen. Arthritis Rheum 39: 877-879, 1996.

20) Takeuchi K, Kaneda K, Kawakami I, Takasaki Y, Hashimoto H. Autoantibodies recognizing proteins copurified with PCNA in patients with connective tissue diseases. Mol Biol Rep 23: 243-246, 1996. 